\title{
"WOODEN" YOU LIKE TO SEE THESE?
}

NORMA ALLEN, 921 - 9th Ave. North, Saskatoon, Saskatchewan. S7N $2 Z 3$

The pictures on the following pages are from a collection that I took along the South Saskatchewan River, mostly within city limits, in 1992. The creatures seen here are not only seldom photographed but are seldom seen. I believe there is good reason for this. All of these ani- mals have exceptional protective colouring, making it possible for us to walk very close to them and miss seeing them entirely. I hope that by publishing the photos, I may be able to alert you to all the wonders that inhabit our lovely river and its shores.

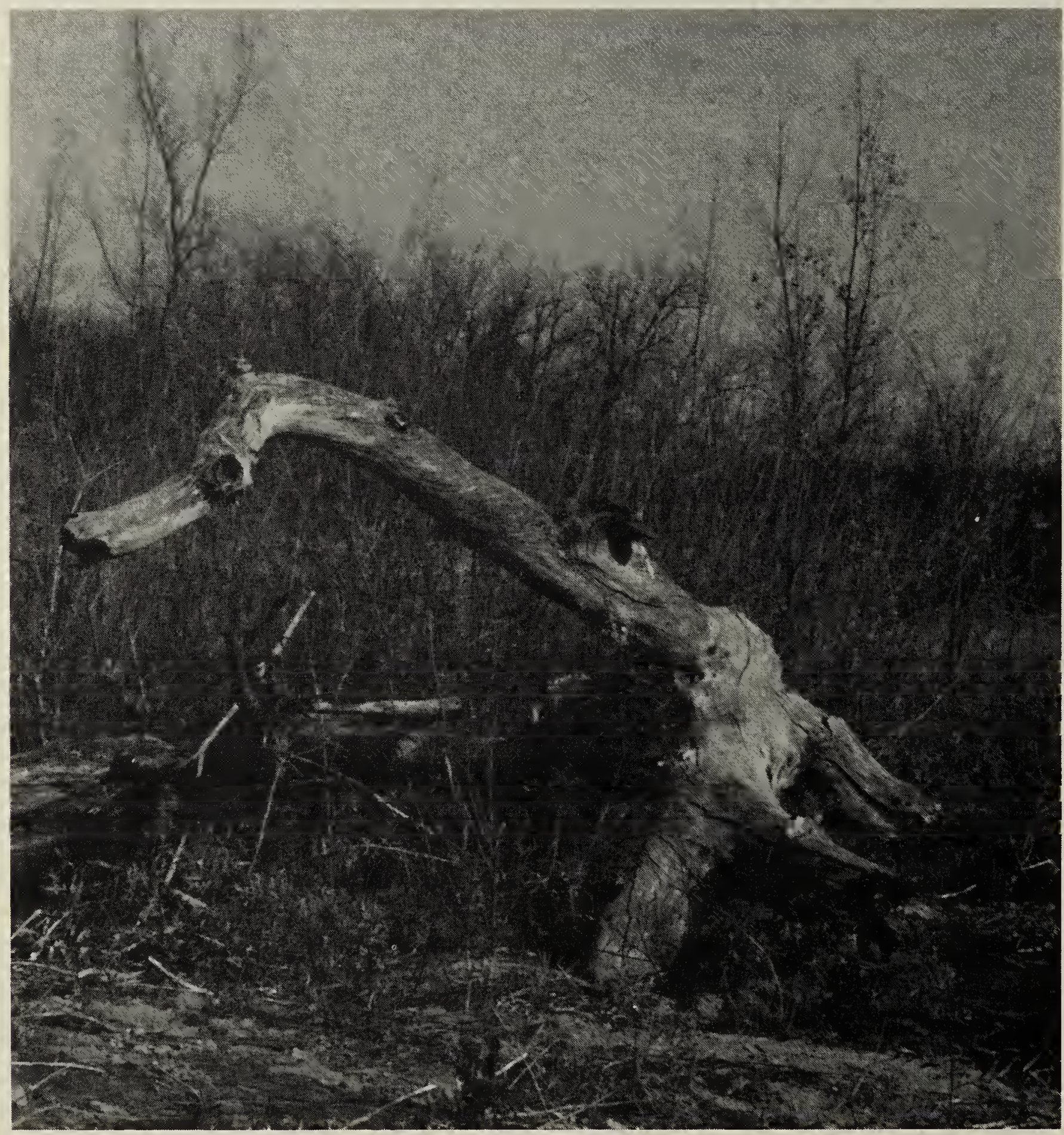

I was very happy to find a new species of horse - Pegasus saskatchewanus. He was about to take flight. 


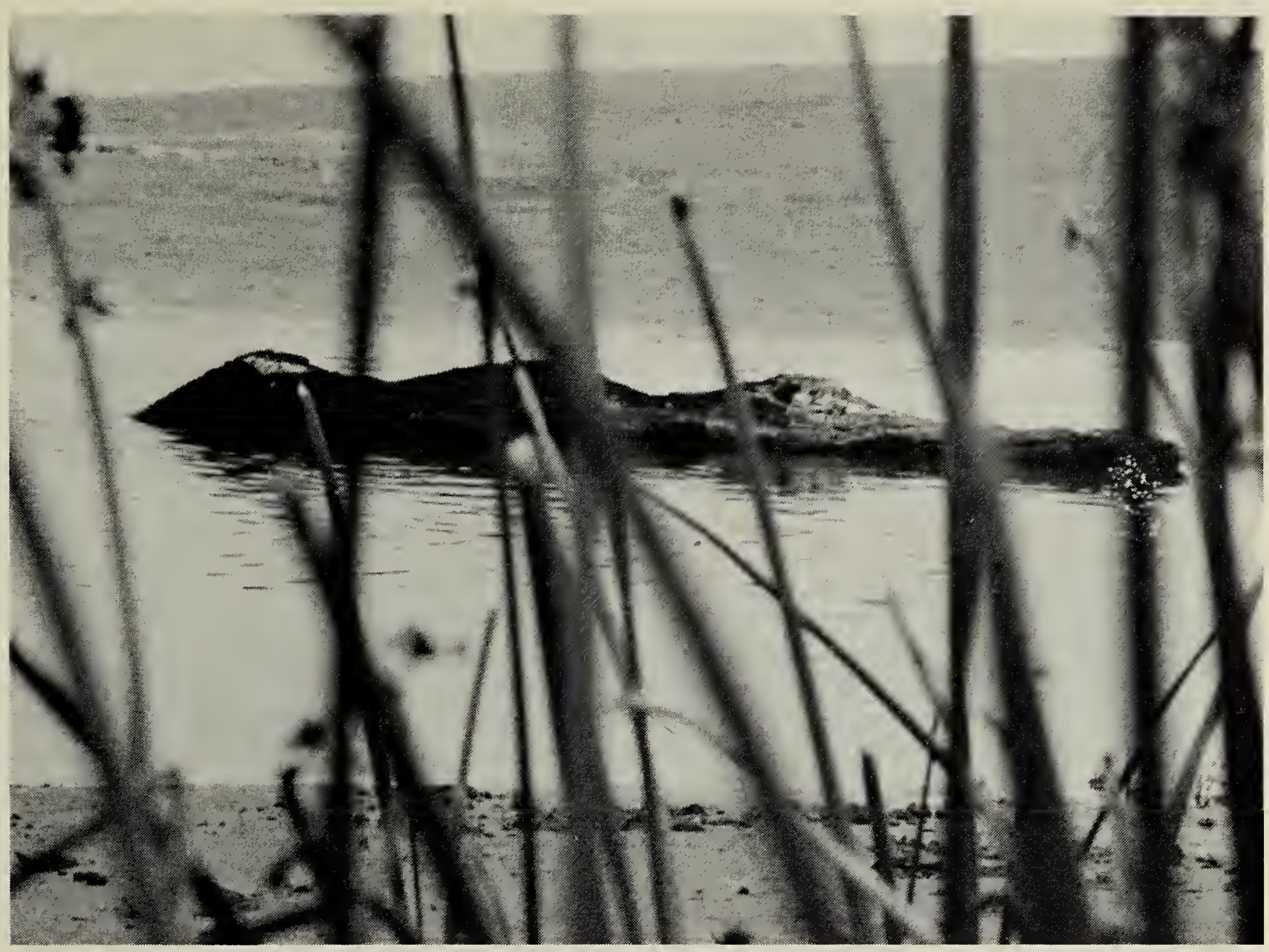

This is the well known South Saskatchewan River Crocodile. I found this to be the most common of all the species seen.

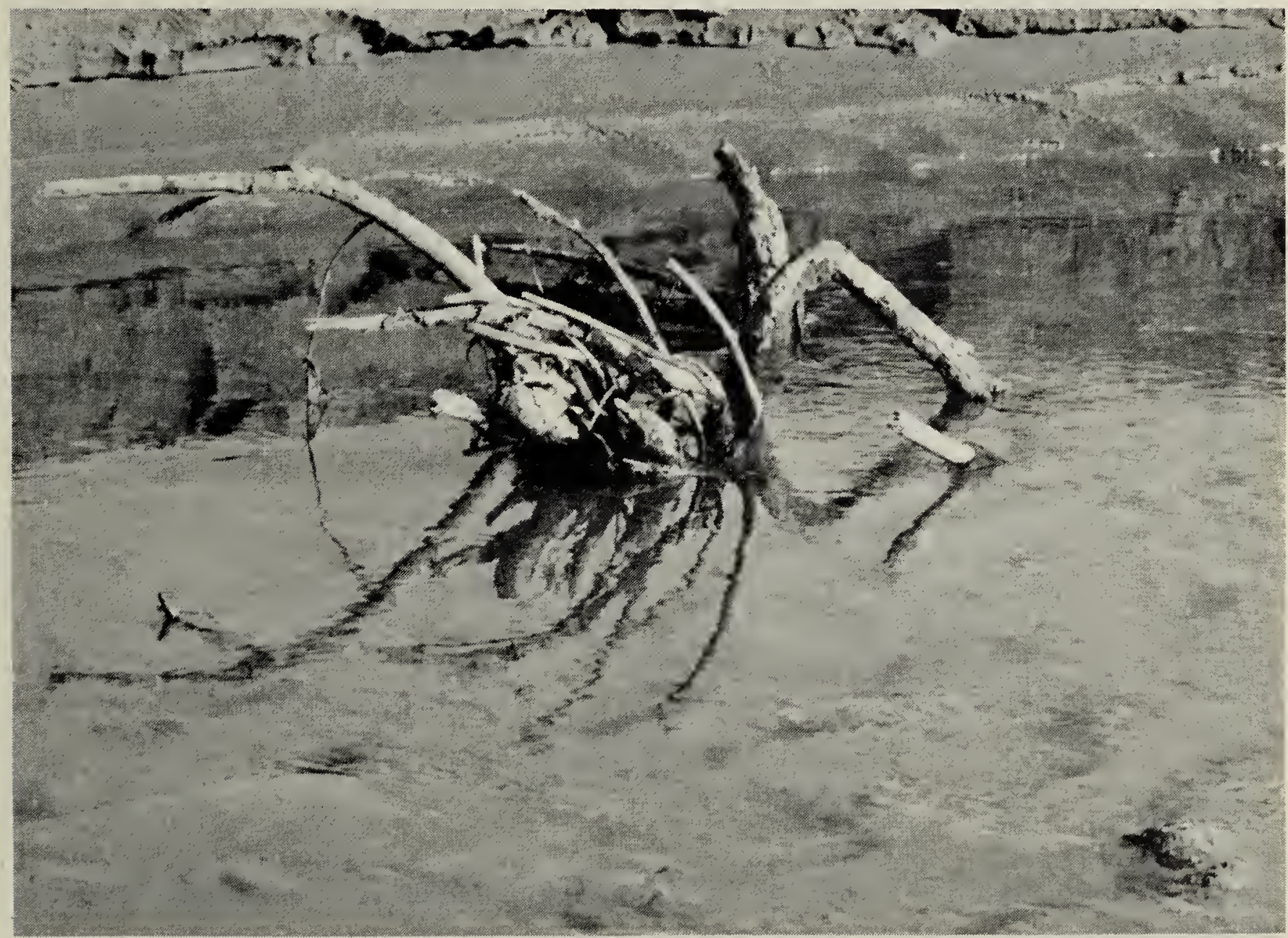

I also found a good many spiders of truly shocking size. This one is the Crab Spider. I didn't wait around for him to reach shore. 


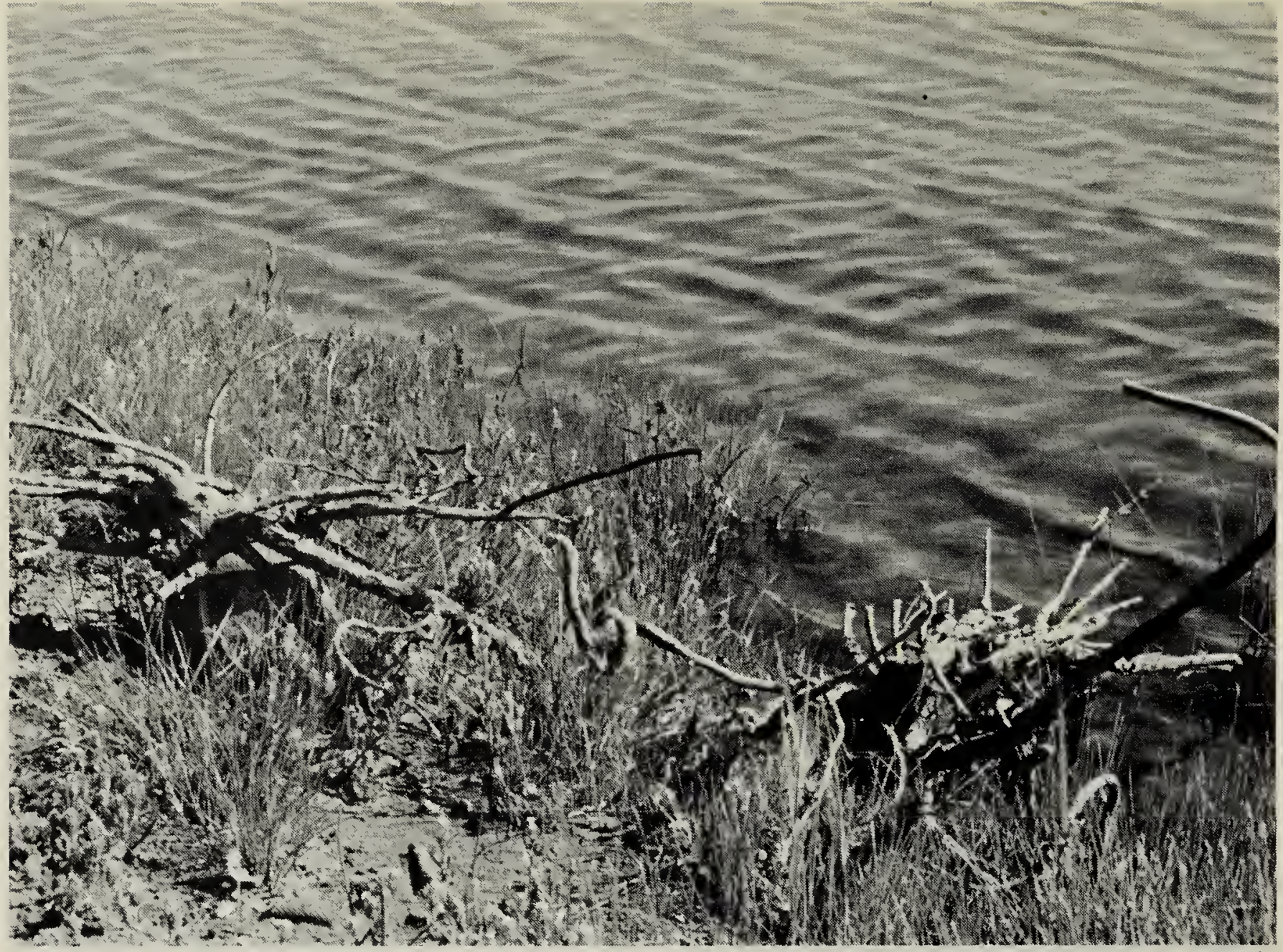

As you can see, there are also scorpions. I couldn't decide whether this pair was at war or whether this was some sort of elaborate mating ritual.

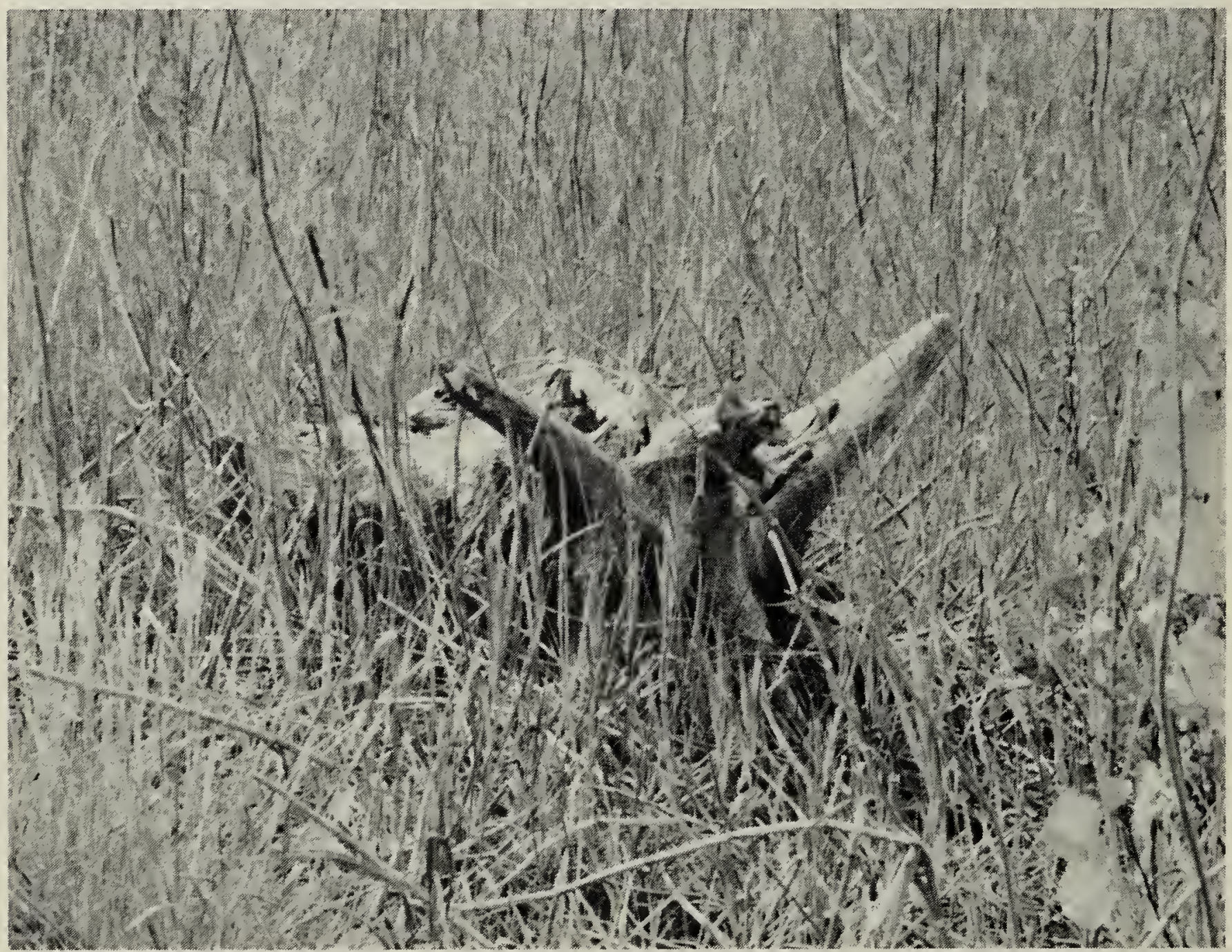

Here is a South Saskatchewan River bovine - grazing. 


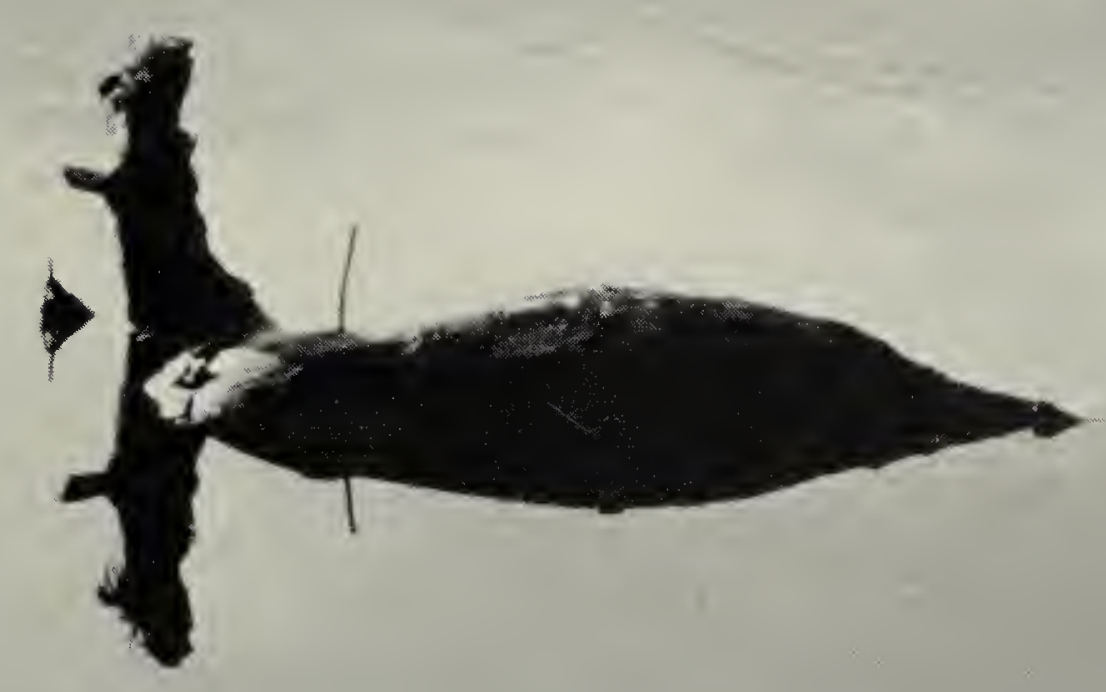

There were not many birds but here is an Aquatic Peacock.

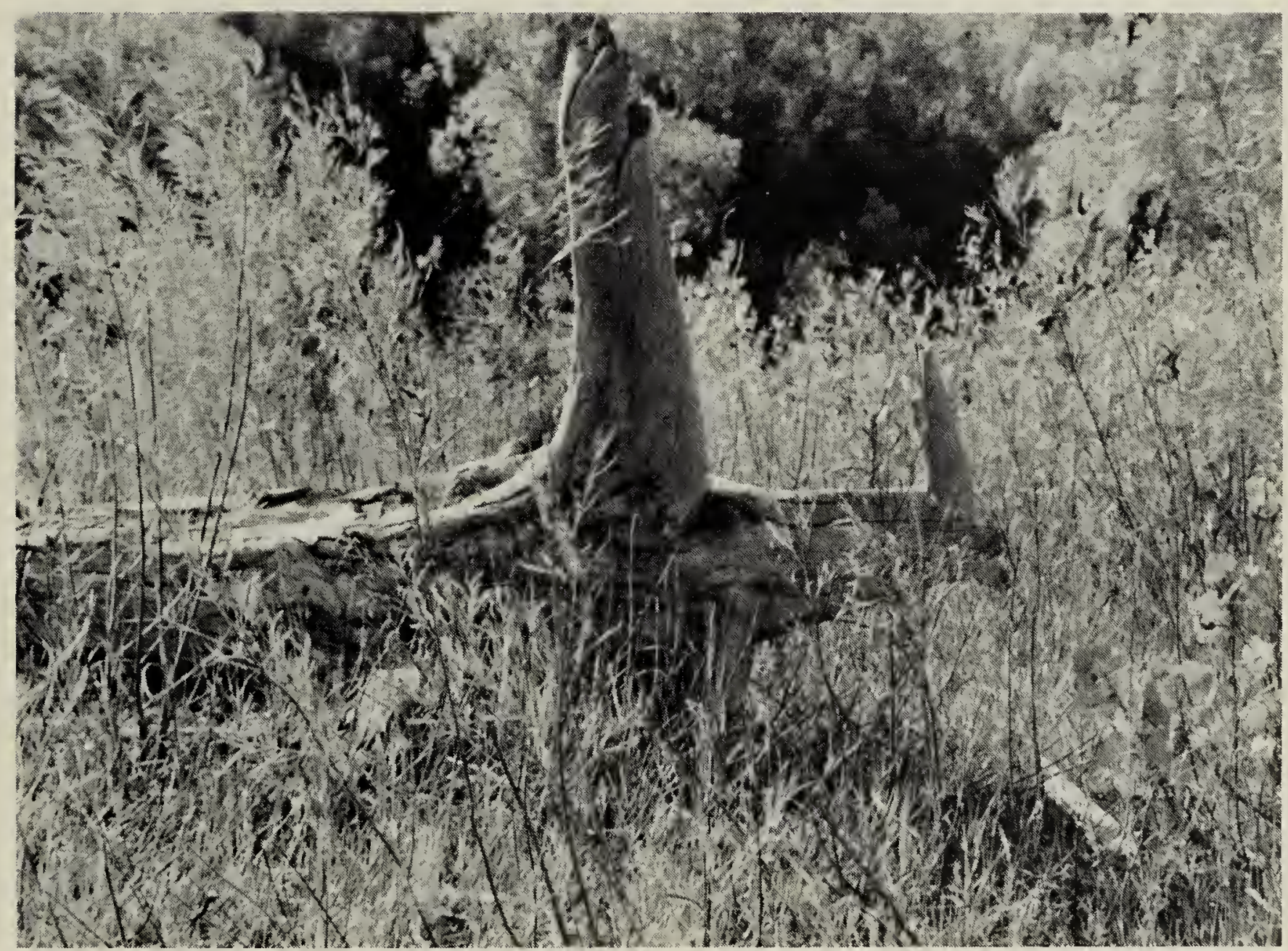

This was a big thrill for me - my first sighting of the Conehead Rhino. Because it was fall, which is their mating season, the forehead cone is in full display. 


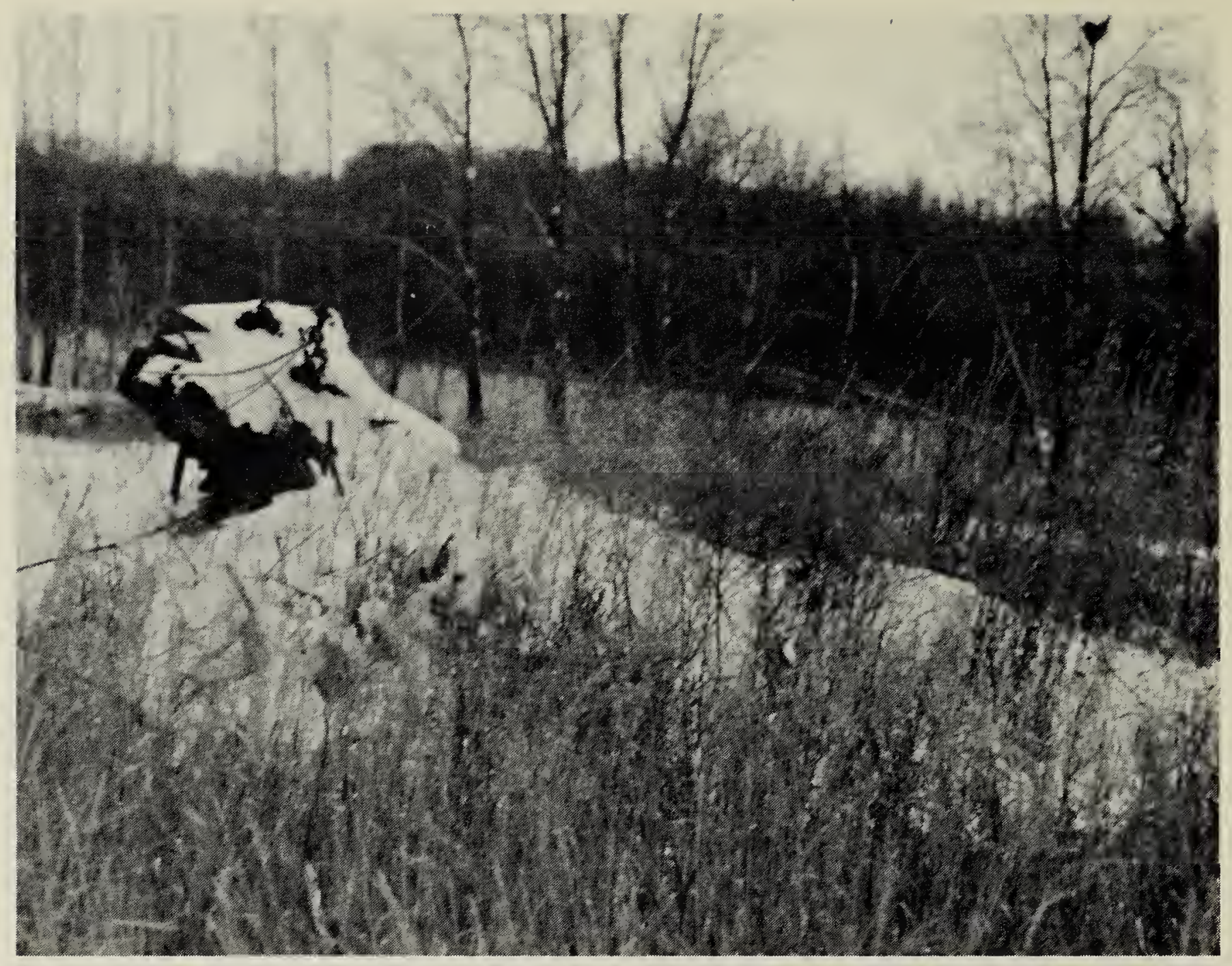

Proof to settle the age-old question: Do Cougars occur in Saskatchewan?

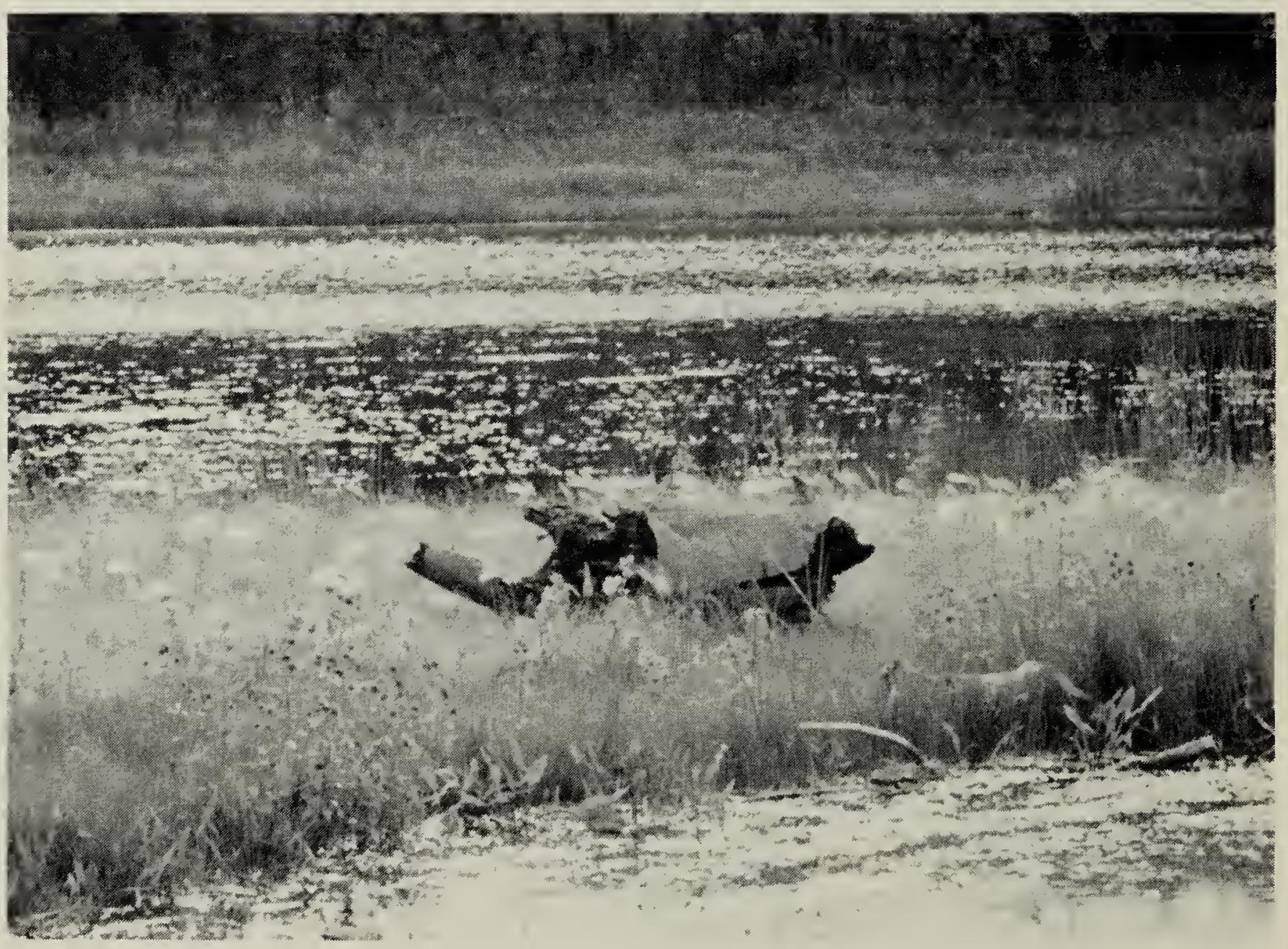

On a warm, sunny morning, a South Saskatchewan River Tortoise comes up on a sand bar to sun itself. 